\title{
Positive Coping: A Unique Characteristic to Pre-Hospital Emergency Personnel
}

\author{
Abbas Ebadi ${ }^{1}$, Razieh Froutan ${ }^{2}$
}

${ }^{1}$ Ph.D. of Nursing Education, Associate Professor, Behavioral Sciences Research Center, Faculty of Nursing, Baqiyatallah University of Medical Sciences, Tehran, Iran

${ }^{2}$ Ph.D. of Nursing Education, Assistant Professor, Department of Medical-Surgical Nursing, School of Nursing and Midwifery, Mashhad University of Medical Sciences, Mashhad, Iran

\section{Type of article: Original}

\begin{abstract}
Introduction: It is important to gain a thorough understanding of positive coping methods adopted by medical emergency personnel to manage stressful situations associated with accidents and emergencies. Thus, the purpose of this study was to gain a better understanding of positive coping strategies used by emergency medical service providers.

Methods: This study was conducted using a qualitative content analysis method. The study participants included 28 pre-hospital emergency personnel selected from emergency medical service providers in bases located in different regions of the city of Mashhad, Iran, from April to November 2016. The purposive sampling method also was used in this study, which was continued until data saturation was reached. To collect the data, semistructured open interviews, observations, and field notes were used.

Results: Four categories and 10 subcategories were extracted from the data on the experiences of pre-hospital emergency personnel related to positive coping strategies. The four categories included work engagement, smart capability, positive feedback, and crisis pioneering. All the obtained categories had their own subcategories, which were determined based on their distinctly integrated properties.

Conclusion: The results of this study show that positive coping consists of several concepts used by medical emergency personnel, management of stressful situations, and ultimately quality of pre-hospital clinical services. Given the fact that efficient methods such as positive coping can prevent debilitating stress in an individual, prehospital emergency authorities should seek to build and strengthen "positive coping" characteristics in prehospital medical emergency personnel to deal with accidents, emergencies, and injuries through adopting regular and dynamic policies.
\end{abstract}

Keywords: Positive coping, Pre-hospital emergency personnel, Content analysis, Qualitative study

\section{Introduction}

Occupations are considered the main sources of stress (1). Chronic psychological pressures due to work-related stress are likewise among those that can lead to mental, physical, and behavioral complications and jeopardize an individual's health status (2). Long-term exposure to negative stressors not only affects physical and mental health but also endangers a person's whole life (3). Wang et al. in their study on mental health status introduced workrelated stress as a crucial factor leading to mental disorders (4). In this respect, emergency medical service (EMS) providers are exposed to numerous risks due to time constraints in performing their duties and making decisions in critical situations as well as other negative stressful physical, emotional, and mental stimuli (5-8). In this regard, Froutan et al. in their study argued that working in pre-hospital emergency situations was unique and stressful and could lead to work-related stress, thus negatively influencing organizational performance (9). The results of the related literature have similarly indicated a nearly $22 \%$ prevalence rate of post-traumatic stress disorder among

\section{Corresponding author:}

Assistant Professor Dr. Razieh Froutan, Department of Medical-Surgical Nursing, School of Nursing and Midwifery, Mashhad University of Medical Sciences, Mashhad, Iran.

Tel: +989151191124, Email: froutanr@mums.ac.ir

Received: November 12, 2016, Accepted: December 14, 2016, Published: January 2017

iThenticate screening: January 01, 2017, English editing: January 03, 2017, Quality control: January 08, 2017

(C) 2017 The Authors. This is an open access article under the terms of the Creative Commons Attribution-NonCommercialNoDerivs License, which permits use and distribution in any medium, provided the original work is properly cited, the use is non-commercial and no modifications or adaptations are made. 
emergency medical technicians. Approximately 6.8\% of emergency technicians have also reported to be at risk of job burnout $(10,11)$. "Resilience" is considered an appropriate strategy to improve mental health status in individuals (12). In this regard, Cutter stated that programs associated with reducing the risks in this area should be oriented toward reinforcing the numerous positive characteristics of resilient populations and give attention to the concept of resilience in terms of chain management in accidents, emergencies, and injuries (13). In fact, one of the underlying factors improving resilience is positive coping, which refers to a dynamic process to adapt positively to bitter and unpleasant experiences $(14,15)$. Accordingly, Sveen identified positive coping strategy as a method to enhance the levels of resilience (16). Similarly, Yong argued that positive adaptation was significantly correlated with levels of resilience as well as other dimensions, including ardency, vigor, and optimism (17). Nowadays, attitudes and theories put forth by authorities regarding pre-hospital emergency care seek to establish and reinforce characteristics of positive coping in EMS personnel in the face of risks associated with accidents and emergencies. In fact, what prevents an individual from breaking down because of stress is the use of methods that can modify the stressors. It also should be noted that such efficient methods arise from multiple characteristics of resilience such as positive coping (18). Given the limited understanding of positive coping mechanisms adopted by EMS personnel to deal with work-related stress and tensions, as well as factors affecting it, in real environments and considering that such understanding as well as determining effective factors are of utmost importance, the main questions of "How does such a mechanism take place in real environments?" and "What are the factors affecting coping with stress and tensions?" have yet to be addressed. Therefore, the purpose of this study was to achieve a better and deeper understanding of the concept of positive coping used by the EMS providers.

\section{Material and Methods}

\subsection{Design}

Qualitative research design with latent content analysis is generally used to study the viewpoints of persons experiencing specific events and situations (19). Consequently, such a method was used, and a synopsis of the experiences of the EMS staff was obtained based on collected data that centered on the viewpoint of the interviewees. The study did not have a priori hypothesis, and the inductive method was used to obtain the different codes and categories. Later they were theoretically ordered based on their properties and dimensions (20, 21).

\subsection{Settings and participants}

We used the purposeful sampling method to recruit the study participants. Hence, we interviewed 28 pre-hospital care professionals (including 20 emergency technicians, three anesthesiology assistants, and five nurses) from the city of Mashhad (Table 1). The inclusion criteria consisted of having previous experience with injury patients, and, in order to have diversity, we choose subjects from various age groups with different education levels, work experiences, and job positions. The exclusion criteria were unwilling to participate in the study and having pervious education on positive coping.

Table 1. Participant characteristics

\begin{tabular}{|l|l|l|l|l|l|l|l|}
\hline No & Age & Position & $\begin{array}{l}\text { Work history } \\
\text { Year })\end{array}$ & No & Age & Position & $\begin{array}{l}\text { Work history } \\
\text { (Year) }\end{array}$ \\
\hline 1 & 30 & Emergency Technician & 9 & 15 & 36 & Emergency Technician & 14 \\
\hline 2 & 31 & Anesthesia Technician & 11 & 16 & 38 & Emergency Technician & 15 \\
\hline 3 & 30 & Emergency Technician & 8 & 17 & 34 & Nurse & 11 \\
\hline 4 & 44 & Emergency Technician & 17 & 18 & 36 & Nurse & 12 \\
\hline 5 & 32 & Nurse & 9 & 19 & 28 & Emergency Technician & 8 \\
\hline 6 & 30 & Nurse & 20 & 32 & Emergency Technician & 9 \\
\hline 7 & 32 & Emergency Technician & 10 & 21 & 28 & Emergency Technician & 7 \\
\hline 8 & 28 & Emergency Technician & 7 & 22 & 37 & Emergency Technician & 12 \\
\hline 9 & 38 & Emergency Technician & 14 & 23 & 38 & Emergency Technician & 15 \\
\hline 10 & 34 & Emergency Technician & 11 & 24 & 32 & Anesthesia Technician & 10 \\
\hline 11 & 38 & Emergency Technician & 15 & 25 & 30 & Emergency Technician & 9 \\
\hline 12 & 28 & Nurse & 6 & 26 & 35 & Emergency Technician & 13 \\
\hline 13 & 42 & Emergency Technician & 16 & 27 & 32 & Anesthesia Technician & 11 \\
\hline 14 & 36 & Emergency Technician & 14 & 28 & 39 & Emergency Technician & 17 \\
\hline
\end{tabular}




\subsection{Data collection and analysis}

Data collection was done using unstructured interviews that included general (e.g., please describe one of your experience of your one day duty in the emergency service) and specific questions, (e.g., please speak about your own experience about coping strategies to deal with a crisis; at the time of a crisis, what problems and issues do you face?; and how do you provide clinical services during a crisis? If required, the interviewee was requested to elaborate upon his or her responses. Each interview lasted about 40-60 minutes and was done in Persian by the first author, while being recorded with the interviewers' consent. Later the interviews were transcribed verbatim and translated into English. The interviewer is an expert in qualitative research and trained in qualitative courses and workshops. The aim of the interviewers was to obtain a deep knowledge of the experiences of the medical staff, and so the interviews, which consisted of data collection, data analysis, and participants' selection, persisted until data saturation was reached. The framework qualitative data analysis method was used to analyze the data, and this encompasses several dissimilar nonetheless vastly interconnected stages (22). In the initial or familiarization stage, after the interviews were completed, the transcribed data verbatim was analyzed several times. The second step identifies a thematic framework stage, which consisted of grouping the transcripts into meaningful units. The summarized meaningful units were code labeled constituting the manifest content. In the third or indexing stage, we compared and contrasted the codes based on their similarities and differences and sorted them into categories and then subcategories and organized all the pertinent codes into data extracts within the named categories. In the fourth or charting stage, we studied the organized extracts for each category and pondered as to whether they formed a coherent pattern. Next, we deliberated upon whether the validity of individual categories with respect to the data set and whether our candidate categories precisely echoed the meaning shown in the data set as a whole. Two researchers independently examined data for different categories. In the fifth or mapping and interpretation stage, we defined and further refined the categories.

\subsection{Ethical considerations}

The Ethics Committee of the Mashhad University of Medical Sciences approved this research project in April 2016 (code: IR.MUMS.REC.1395.99). Before starting the study, the participants were informed about the purpose of the study, and they were assured they could withdraw from the study whenever they desired without repercussions. The participants then signed an informed consent form.

\subsection{Trustworthiness}

Maximum variation of sampling was used to validate the dependability and credibility of the data (23) along with member checking and peer debriefing. A summary of the interviews was given to nine participants to confirm the researchers accurately depicted their viewpoints and experiences. Peer checking was done by two doctoral nursing students who received the transcriptions and a summary of the analysis process. If there were any differences, then they were resolved by discussions (24). Our lengthy presence in the field (from April 2016 to November 2016) allowed us to create trusting and supportive communication links with the interviewees; thus allowing us to accurately collect data.

\section{Results}

In the present study, the experiences and perceptions of participants adopting positive coping mechanisms against terrible accidents, emergencies, and disasters have been explored. In this respect, data analysis led to the establishment of four main concepts, including work engagement, smart capability, positive feedback, and crisis pioneering (Table 2).

\subsection{Work Engagement}

Work engagement was one of the extracted concepts in the analysis of experiences and perceptions of participants in the present study. This category was comprised of two subcategories of "loyalty to system" and "accountability towards victims." In this respect, it was argued that special bias toward their profession among EMS personnel has caused them to act loyally. In terms of loyalty to the system, the study participants believed that they had used all their vigor and abilities in order to fulfill organizational goals and serve the public. In this regard, one of the participants (no. 11) stated: “... we have a kind of enthusiasm and eagerness towards pre-hospital emergency ... we have not left the profession because other people starting such a profession may not have the necessary competence in this respect ...we pay homage to this profession ...." The EMS personnel also assumed themselves to be in charge of dealing with the medical conditions of victims, and they had accepted their share of responsibility in terms of performing the related procedures. They also believed that the life of victims was a heavy responsibility on their shoulders. In this respect, one of the participants (no. 19) said: "During the mission, I was taking care of the 
breathing and consciousness of a baby suffering from a burn ... but I noticed a sudden reduction in vital signs ... I have a heavy responsibility ... there is too much stress ...."

Table 2. Categories and subcategories of positive coping pre-hospital emergency personnel and some extracted codes

\begin{tabular}{|c|c|c|c|}
\hline Theme & Categories & Subcategories & Codes \\
\hline \multirow[t]{10}{*}{$\begin{array}{l}\text { Positive } \\
\text { coping }\end{array}$} & \multirow[t]{2}{*}{$\begin{array}{l}\text { Work } \\
\text { engagement }\end{array}$} & Loyalty to system & $\begin{array}{l}\text { 1) Having a passion for pre-hospital emergency work; } \\
\text { 2) Endeavoring to maintain the organization by } \\
\text { qualified individuals }\end{array}$ \\
\hline & & $\begin{array}{l}\text { Accountability toward } \\
\text { victims }\end{array}$ & $\begin{array}{l}\text { 1) Endeavoring to take the injured quickly to the } \\
\text { treatment centers; 2) Endeavoring to sustain the vital } \\
\text { signs of the injured; 3) Endeavoring to keep the injured } \\
\text { alive }\end{array}$ \\
\hline & \multirow[t]{3}{*}{$\begin{array}{l}\text { Smart } \\
\text { capability }\end{array}$} & Judgment/decision-making & $\begin{array}{l}\text { 1) Having correct judgment at the accident scene; } 2 \text { ) } \\
\text { Making quick and vital decisions at the accident scene }\end{array}$ \\
\hline & & Optimism & $\begin{array}{l}\text { 1) Believing that difficulties at the accident scene will } \\
\text { pass; 2) Having hope to overcome the difficulties faced } \\
\text { at an accident scene; 3) Encountering difficulties with } \\
\text { ease and calmness }\end{array}$ \\
\hline & & Self-efficacy & $\begin{array}{l}\text { 1) Controlling highly emotional situations at the } \\
\text { accident scene; 2) Keeping the peace at the accident } \\
\text { scene; 3) Inviting aggressive people to be calm }\end{array}$ \\
\hline & \multirow[t]{2}{*}{$\begin{array}{l}\text { Crisis } \\
\text { pioneering }\end{array}$} & $\begin{array}{l}\text { Readiness to perform new } \\
\text { missions }\end{array}$ & $\begin{array}{l}\text { 1) Volunteering because of being close to the accident } \\
\text { scene; 2) Volunteering because of the high number of } \\
\text { injured people }\end{array}$ \\
\hline & & $\begin{array}{l}\text { Volunteer actions to counter } \\
\text { crises }\end{array}$ & $\begin{array}{l}\text { 1) Being present during accidents and disasters; 2) } \\
\text { Volunteering to save human lives }\end{array}$ \\
\hline & \multirow[t]{3}{*}{$\begin{array}{l}\text { Positive } \\
\text { feedback }\end{array}$} & $\begin{array}{l}\text { Effectiveness of clinical } \\
\text { service delivery }\end{array}$ & $\begin{array}{l}\text { 1) Being satisfied with the effectiveness at the accident } \\
\text { scene; 2) Being pleased with doing professional tasks } \\
\text { on time }\end{array}$ \\
\hline & & $\begin{array}{l}\text { Satisfaction of victims with } \\
\text { clinical services }\end{array}$ & $\begin{array}{l}\text { Being motivated by the satisfaction of the injured } \\
\text { persons }\end{array}$ \\
\hline & & $\begin{array}{l}\text { Positive views with the } \\
\text { authorities/employee } \\
\text { motivation }\end{array}$ & $\begin{array}{l}\text { 1) Becoming motivated from participating in the } \\
\text { decision-making process; } 2 \text { ) Being motivated because } \\
\text { of the satisfaction of the authorities; } 3 \text { ) Increasing } \\
\text { one's motivation when the authorities responded well }\end{array}$ \\
\hline
\end{tabular}

\subsection{Smart Capability}

Another category in the present study was "smart capability." In this respect, the pre-hospital emergency personnel felt empowered in terms of providing proper care for victims through their own competence, expertise, and skills. Judgment/decision-making, optimism, and self-efficacy were extracted as the subcategories associated with smart capability. The study participants believed that if victims' lives were threatened, they should seize the opportunity and incubate them based on their own judgment and quick decisions; because loss of time would cause death. In this regard, one of the EMS personnel (no. 26) reiterated: “... the victim with a chest burn needed cardiopulmonary resuscitation (CPR) ... abroad and deep burn all over his chest had made cardiac massage useless ... the injured victim was in urgent need of scartomy ... I immediately did it ...." In terms of the necessity to make quick decisions in order to intubate the victim, one of the participants (no. 17) also stated: “... in the first minutes, the victim was confused ... her breathing rate was slow... she answered us slowly ... in a wrap-up, I diagnosed her with decreased level of consciousness ... I made up my mind ... then I quickly intubated the victim ..." The second subcategory of smart capability was optimism among medical emergency personnel. The EMS technicians argued that they could make use of more effective coping strategies in the face of mental pressures. In their hard and demanding missions, such personnel attempted to assure adequate clinical services. Considering psychological traumas, they could process the situation through adaptation. In this regard, an emergency technician added: “... some of the missions are demanding and difficult ... but problems associated with the scenes of an accident are transient ... my colleague and I could save the victim's life with concentration and effort ...." In terms of "self-efficacy," the study participants 
believed that, although the scenes of accidents and emergencies were replete with tensions and stress, they endeavored to control all steps of the missions and tackle possible barriers undermining the delivery of clinical services. In this respect, one of the medical emergency personnel (no. 15) said: "People were agitated at the scene of the accident ... they had made everything difficult for us ... I controlled them with calmness and high selfconfidence ... I also asked them to leave the scene ... so we could help the victims ...."

\subsection{Positive Feedback}

Positive feedback was one of the other extracted concepts in the given analysis. It included three subcategories of "effectiveness of clinical service delivery," "satisfaction of victims with clinical services," "positive views by authorities," and "employee motivation." During the interviews with the EMS personnel, these two points were highlighted: pre-hospital emergency is the frontline of care and treatment in which the most serious emergency cases are accommodated and how services are provided in the emergency department as a symbol of the general status of services in society. The given personnel assumed that quality of examination as well as clinical services provided along with their effectiveness could lead to patient satisfaction and, as a result, employee satisfaction. In this regard, one of the medical emergency personnel (no. 13) added: “... I rushed to examine a two-year boy who had drowned in cold water ... I started cardiopulmonary resuscitation (CPR) ... the child fortunately recovered ... he had defecated ... I took off his clothes ... I covered him with my jacket ... that day ... saving the life of a child motivated me ... I decided to be more determined in my profession ... and work hard despite problems ... and enjoy ...." Positive views by authorities were the final subcategory extracted from the analysis of positive feedback. The study participants cited further support by authorities and their involvement in decision-making by authorities as other factors affecting positive feedback. In this respect, one of the EMS personnel (no. 2) stated: “... Our participation in decision-making for the EMS bases with the authorities ... good treatment by authorities due to their satisfaction with us ... can heavily motivate us to stay in this profession."

\subsection{Crisis Pioneering}

Another characteristic unique to the concept of "positive coping" is crisis pioneering, which has two subcategories: "readiness to perform new missions" and "volunteer actions to counter crises." In this regard, the participants argued that, if they were near the accident site and there were a high number of victims, they would announce their readiness to the EMS center. In this regard, a participant (no. 5) maintained that: “... I was returning from a mission ... the EMS center messaged an accident ... with a high number of victims ... in critically bad conditions ... we were close to the scene of accident ... we coordinated with the EMS center and then went straight to the scene of the accident ..." In terms of volunteering to counter the crises, one of the medical emergency technicians said that:"... the personality traits of emergency personnel are such that they quickly volunteer if everyone asks for help ... we go and rescue people ... for example ... although it was very difficult to access the city of Bam following the earthquake ... and there were so many problems ... we were dispatched to the scene through the system as volunteers ..."

\section{Discussion}

Using the experiences of pre-hospital emergency personnel and the analysis of data obtained in the present study, we extracted four main categories of work engagement: smart capability, crisis pioneering, and positive feedback. These categories also had their own subcategories based on their distinctly integrated properties. This preliminary study done in Iran employed a qualitative content analysis method to examine the experiences of pre-hospital emergency personnel in terms of positive coping and to address the research question of "How are the experiences and perceptions of pre-hospital emergency personnel towards positive coping?" According to the results of the present study, pre-hospital emergency personnel had a particular bias toward their profession, and they had made attempts to fulfill their duties in this respect. They had selected this profession and acted faithfully. They also believed that this profession must remain in the hands of qualified people who continue their activities in order to save the lives of victims. In fact, the EMS personnel showed emotional reactions to their profession and affiliated organization, and they tried to carry out their duties with higher quality through a sense of accountability toward the victims. In this regard, the results of studies by Avery and Rurkkhum showed that performance was not simply reduced to competence, eligibility, or skills in employees; rather it was dependent upon the way personnel displayed emotional reactions in their profession and affiliated organization $(25,26)$. In the study by Macey et al., the findings also showed that employees with higher levels of work engagement were encouraged by intrinsic stimuli such as opportunities for job promotion, value, and fair treatment rather than financial rewards or other extrinsic factors (27). In fact, employees endowed with high levels of work engagement considered their profession significant, motivating, and challenging because they were inclined to apply their knowledge, skills, and resources to develop 
their work skills $(28,29)$. In this respect, Modi claimed that work commitment and engagement were beyond passive loyalty, and they included active bonds with an organization in which personnel tended to make considerable efforts to achieve organizational welfare as one example of staff loyalty (30). Smart capability was similarly taken into account as one of the factors affecting the EMS personnel in the face of crises that could lead to the development of resistance in difficult conditions. The findings of this study showed that "judgment/decisionmaking" by EMS personnel along with their skills were of utmost importance such that they could use their own knowledge and skills to perform independent nursing interventions for patients based on their self-esteem and selfconfidence. In this respect, studies by Moadab and Nasirpour revealed that medical emergency personnel played the role of an implementer $(31,32)$, and their interventions as well as health care services were provided based on their independent judgment, decision-making skills, and prioritization (32). Because EMS personnel need to be empowered decision-makers in the variable conditions of victims and uncertain clinical environments, the authority and the rights granted to them in decision-making abilities gives them a sense of empowerment. The results of this study in terms of "giving authority and rights to make decisions" were consistent with the findings by White. In this regard, the author concluded that this community of personnel could better control the environment, and they could easily make and implement decisions (33). However, Krairikshh reported that the amount of official authority did not have a significant effect on performance and clinical decisions in nurses (34). Another reason for the capability of the EMS personnel was their optimism to deal with crises. Based on the study results, emergency technicians persisted in reaching the goals when they were challenged on missions due to having a sense of self-confidence. In their views, adversities in missions could be manipulated and controlled. In fact, optimism in medical emergency personnel was considered as one of their most important individual factors affecting the choice of strategies to meet the challenges raised during missions. In this regard, studies have shown that optimistic individuals go through the daily events of their lives with a more positive manner, and they anticipate more positive consequences (35). Other results associated with the present study have shown that EMS technicians were required to be flexible in order to adapt themselves with accidents and crises through planning, especially when encountered by difficult missions. The results of a study by Thompson also showed that optimistic people make use of control strategies such as attempt, controlled thought, and logical analysis (36). Considering self-efficacy as another reason for the capability of the EMS personnel, the results of this study have indicated that medical emergency personnel make used of their own competence and expertise in missions and controlled the circles of people around the scenes of accidents. In fact, they could provide clinical services through scene management. Lalianpour stated that, when individuals had the required capabilities, they were endowed with a sense of self-efficacy, or they felt they had the essential competence and expertise for successful fulfillment of their duties (37). Crisis pioneering was one of the other concepts obtained from the experiences of medical emergency personnel with positive coping. The results of the present study showed that the pioneering characteristics of the EMS personnel could lead to more stability in their professions. In this regard, Crunt stated that people who pioneered in doing activities had initiative and expanded the scope of their roles. Empirical evidence also suggested that the given category was positively correlated with organizational consequences such as job performance and stress tolerance in demanding and difficult occupations (38).

Another concept extracted from the experiences of medical emergency personnel in terms of positive coping was receiving positive feedback. The findings of this study have shown that victim satisfaction with clinical services provided by the EMS personnel was considered as positive feedback. In fact, dissatisfaction of people with healthcare services would bring about adverse consequences that could lead to their disconnection with the prehospital emergency system and creation of negative feedback towards the EMS personnel. In a study conducted by Bovdorksy et al. in the United States, it was found that the quality of health care delivery could have the greatest effect on the level of satisfaction in victims (39). Focusing on the relationship between patients' levels of satisfaction compared with those in nurses, Tzeng reported that nurses' levels of satisfaction were directly correlated with those in patients (40). In this respect, Omidvari stated that patient satisfaction leads to a sense of contentment in health care personnel. In line with the findings of this study, the present study also showed that patient satisfaction could provide positive feedback in personnel according to their experiences, which ultimately could lead to improvement of positive coping skills and resilience in stressful situations and crises (41). Considering the concept of positive feedback, another concept extracted from the experiences of the EMS providers was the attitudes of authorities to personnel. According to the considerable and serious tasks assigned to EMS centers in terms of maintaining and promoting public health, authorities were required to involve medical emergency personnel in the decision-making processes of the organization. Today, one organizational strategy is to grant more responsibilities for decision-making to the personnel because their participation will enhance organizational performance (42). The results of the present study suggest that medical emergency personnel have considered collaborative decisionmaking by authorities as one of the best working conditions affecting motivation, job satisfaction, and promotion of 
quality of services. However, Zandi showed that nurses have little feeling toward taking part in decision-making processes (43). The experiences of the EMS personnel in this study revealed that several factors such as behaviors of authorities could have a positive effect on their motivation. In fact, officials could satisfy motivation through its recognition and prediction in medical emergency personnel. In this regard, Vali estimated that one-third of the working and operational staff in the EMS centers had low levels of work-related motivation (44). Therefore, managers and officials should consider the fact that motivated human forces can have an effect on the survival and dynamicity of an organization as well as the fulfillment of its policies and strategies (45). Meanwhile, managers who accentuate human values believe that increased efficiency is the result of improved motivation (46).

\section{Conclusions}

Although the results of the studies in terms of understanding the experiences of pre-hospital emergency personnel toward positive coping in the face of crises cannot be generalized worldwide, and it can be only applied to similar cultures and situations, such research studies can have their own conclusions and implications. First, this study has shown that different factors can have an effect on the formation of "positive coping" in medical emergency personnel. The results of this study have also shown that some factors such as "work engagement" were consistent with the results of similar studies, but factors such as positive feedback, pioneering crisis, and smart capability were considered as the underlying factors affecting positive coping. Given the fact that efficient methods such as positive coping can prevent debilitating stress in an individual, pre-hospital emergency authorities should seek to build and strengthen positive coping characteristics in pre-hospital medical emergency personnel to deal with the risks associated with accidents, emergencies, and injuries through adopting regular and dynamic policies.

\section{Acknowledgments:}

The authors would like to express their gratitude to all the personnel who participated in this study. The authors express their appreciation toward scientific and financial support of the Mashhad University of Medical Sciences (grant number: IR.MUMS.REC.1395.99).

\section{Conflict of Interest:}

There is no conflict of interest to be declared.

\section{Authors' contributions:}

Both authors contributed to this project and article equally. Both authors read and approved the final manuscript.

\section{References:}

1) Rezaei SH, Hosseini MA, Falahi M. Effect of communication skills teaching in job stress level among nurses occupying in rehabilitation center. TUMJ. 2006; 64(1): 21-6.

2) Rahmani F, Behshid M, Zamanzadeh V, Rahmani F. Relationship Between General Health, Occupational Stress and Burnout in Critical Care Nurses of Tabriz Teaching Hospitals. Iran Journal of Nursing. 2010; 23(66): 54-63.

3) Ganji H. Mental Health. Tehran: Arasbaran; 2012.

4) Wang W, Kong AW, Chair SY. Relationship Between Job Stress Level and Coping Strategies Used by Hong Kong Nurses Working in an Acute Surgical Unit. Appl Nurs Res. 2011; 24(4): 238-43. doi: 10.1016/j.apnr.2009.09.003. PMID: 20974076.

5) Motie MR, Kalani MR, Samadi A, Eshaghi H, Ghobadi P. Prevalence of job stressorsin male pre-hospital emergency technicians. The quarterly journal of fundamentals of mental health. 2010; 12(1(45)): 420-9.

6) Essex B, Scott LB. Chronic Stress and Associated Coping Strategies Among Volunteer EMS Personnel. Prehosp Emerg Care. 2008; 12(1): 69-75. doi: 10.1080/10903120701707955. PMID: 18189181.

7) Sofianopoulos S, Williams B, Archer F, Thompson B. The exploration of physical fatigue, sleep and depression in paramedics: a pilot study. Australasian Journal of Paramedicine. 2011; 9(1).

8) Garrosa E, Moreno-Jimenez B, Liang Y, González JL. The relationship between socio-demographic variables, job stressors, burnout, and hardy personality in nurses: An exploratory study. Int J Nurs Stud. 2008; 45(3): 418-27. doi: 10.1016/j.ijnurstu.2006.09.003. PMID: 17109862.

9) Froutan R, Khankeh HR, Fallahi M, Ahmadi F, Norouzi K. Pre-hospital burn mission as a unique experience: A qualitative study. Burns. 2014; 40(8): 1805-12. doi: 10.1016/j.burns.2014.04.010. PMID: 24907192. 
10) Bennett P, Williams Y, Page N, Hood K, Woollard M. Levels of mental health problems among UK emergency ambulance workers. Emergency Medicine Journal. 2004; 21(2): 235-6. doi: 10.1136/emj.2003.005645.

11) Van Der Ploeg E, Kleber RJ. Acute and chronic job stressors among ambulance personnel: predictors of health symptoms. Occup Environ Med. 2003; 60(suppl 1): i40-6. doi: 10.1136/oem.60.suppl_1.i40. PMID: 12782746.

12) Hosseini Ghomi T, Salimi Bajestani H. Effectiveness of Resilience Training on Stress of Mothers Whose Children, Suffer from Cancer in Imam Khomeini Hospital of Tehran. Health Psychology. 2013; 1(4): 97 109.

13) Cutter SL, Barnes L, Berry M, Burton C, Evans E, Tate E, et al. A place-based model for understanding community resilience to natural disasters. Global environmental change. 2008; 18(4): 598-606. doi: 10.1016/j.gloenvcha.2008.07.013.

14) Luthar SS, Cicchetti D. The construct of resilience: Implications for interventions and social policies. Dev Psychopathol. 2000; 12(4): 857-85. doi: 10.1017/S0954579400004156. PMID: 11202047, PMCID: PMC1903337.

15) Masten AS. Ordinary magic: Resilience processes in development. Am Psychol. 2001; 56(3): 227-38. doi: 10.1037/0003-066X.56.3.227. PMID: 11315249.

16) Sveen J, Ekselius L, Gerdin B, Willebrand M. A prospective longitudinal study of posttraumatic stress disorder symptom trajectories after burn injury. J Trauma. 2011; 71(6): 1808-15. doi: 10.1097/TA.0b013e31822a30b8. PMID: 21841510.

17) Yang Z, Wang Jq, Zhang BZ, Zeng Y, Ma Hp. Factors influencing resilience in patients with burns during rehabilitation period. International Journal of Nursing Sciences. 2014; 1(1): 97-101. doi: 10.1016/j.ijnss.2014.02.018.

18) Momeni K, Akbari M, Atash Zadeh Shourideh F. Relationship between Resilience and Burnout of Nurses. J Teb-o-Tazkieh. 2010; 3(4): 29-36. doi: 10.1016/S0140-6736(01)05627-6.

19) Malterud K. Qualitative research: standards, challenges, and guidelines. The lancet. 2001; 358(9280): 4838.

20) Speziale HS, Streubert HJ, Carpenter DR. Qualitative research in nursing: Advancing the humanistic imperative: Lippincott Williams \& Wilkins; 2011.

21) Corbin J, Strauss A. Basics of qualitative research: Techniques and procedures for developing grounded theory. Sage publications; 2014.

22) Bryman A, Burgess B. Analyzing Qualitative Data. Taylor \& Francis; 2002.

23) Graneheim UH, Lundman B. Qualitative content analysis in nursing research: concepts, procedures and measures to achieve trustworthiness. Nurse Educ Today. 2004; 24(2): 105-12. doi: 10.1016/j.nedt.2003.10.001. PMID: 14769454.

24) Polit DF, Beck CT. Nursing research: Generating and assessing evidence for nursing practice: Lippincott Williams \& Wilkins; 2008.

25) Avery DR, McKay PF, Wilson DC. Engaging the aging workforce: the relationship between perceived age similarity, satisfaction with coworkers, and employee engagement. J Appl Psychol. 2007; 92(6): 1542-56. doi: 10.1037/0021-9010.92.6.1542. PMID: 18020795 .

26) Rurkkhum S. The relationship between employee engagement and Organizational Citizenship Behavior in Thai organizations. dissertation. 2010. Available from: http://hdl.handle.net/11299/100890.

27) Macey WH, Schneider B. The meaning of employee engagement. Industrial and organizational Psychology. 2008; 1(1): 3-30. doi: 10.1111/j.1754-9434.2007.0002.x.

28) Bakker AB, Demerouti E. Towards a model of work engagement. Career development international. 2008; 13(3): 209-23. doi: 10.1108/13620430810870476.

29) Schaufeli WB, Salanova M, González-Romá V, Bakker AB. The measurement of engagement and burnout: A two sample confirmatory factor analytic approach. Journal of Happiness studies. 2002; 3(1): 71 -92. doi: 10.1023/A:1015630930326.

30) Allen NJ, Meyer JP. The measurement and antecedents of affective, continuance and normative commitment to the organization. Journal of occupational psychology. 1990; 63(1): 1-18. doi: 10.1111/j.2044-8325.1990.tb00506.x.

31) Moadab H, Bahramy F. Challenges and problems of performing triage from the perspective of nurses in selected hospitals. 3rd International Congress on Health, Medication and Crisis Management in Disaster. Tehran; 2007. 
32) Nasiripur A, Bahadori $M$, Tofighi $S$, Gohari M. Prehospital emergency performance in Iran View of comprehensive coverage plan. Journal of Critical care nursing. 2010; 2(4): 3-4.

33) White AH. Clinical decision making among fourth-year nursing students: An interpretive study. J Nurs Educ. 2003; 42(3): 113-20. doi: 10.3928/0148-4834-20030301-06. PMID: 12661711.

34) Krairiksh M, Anthony MK. Benefits and outcomes of staff nurses' participation in decision making. J Nurs Adm. 2001; 31(1): 16-23. doi: 10.1097/00005110-200101000-00005. PMID: 11198837.

35) Kivimäki M, Vahtera J, Elovainio M, Helenius H, Singh-Manoux A, Pentti J. Optimism and pessimism as predictors of change in health after death or onset of severe illness in family. Health Psychol. 2005; 24(4): 413-21. doi: 10.1037/0278-6133.24.4.413. PMID: 16045377.

36) Thompson A, Gaudreau P. From optimism and pessimism to coping: The mediating role of academic motivation. International Journal of Stress Management. 2008; 15(3): 269-88. doi: 10.1037/a0012941.

37) Lalianpour N, Dousti N, Mohammadzade A. Empowerment and Organizational Commitment concepts. Insurance world update. 2011; 163: 24-39.

38) Crant JM. Proactive behavior in organizations. Journal of management. 2000; 26(3): 435-62. doi: $10.1177 / 014920630002600304$.

39) Boudreaux ED, D'Autremont S, Wood K, Jones GN. Predictors of emergency department patient satisfaction: stability over 17 months. Acad Emerg Med. 2004; 11(1): 51-8. PMID: 14709428.

40) Tzeng HM, Ketefian S. The Relationship Between Nurses' Job Satisfaction and Inpatient Satisfaction: An Exploratory Study in a Taiwan Teaching Hospital. J Nurs Care Qual. 2002; 16(2): 39-49. doi: 10.1097/00001786-200201000-00005. PMID: 11797477.

41) Omidvari S. Measurement of patient's satisfaction from emergency unit of Tehran university of medical sciences. Researches of medical sciences. 2002.

42) Govindarajulu N, Daily BF. Motivating employees for environmental improvement. Industrial Management \& Data Systems. 2004; 104(4): 364-72. doi: 10.1108/02635570410530775.

43) Asad Zandi M, Ebadi A, Karami Zarchi A, Gholami M, Farsi Z. The relationship between nurse's perception of their head nurses empowerment behaviors and their own work effectiveness. Annals of military and health sciences research. 2007; 5(1): 1133-9.

44) Vali L, Ghorbani NR, Shirkhani H, Zol AF. Comparison of the job motivation of staff worker with management emergency medical center's operational staff. Iranian journal of nursing research. 2015; 10(38): 61-70.

45) Karimi R. Planning and human resources management. Center for Applied Research in Higher Education. Komiteh Emdad of Imam Khomeini. 2002.

46) Taghavi Larijani T, Parsa Yekta Z, Kazemnejad A, Mazaheri A. Outcomes of the performance appraisal and its relation with nurses job motivation. Hayat. 2007; 12(4): 39-45. 